\title{
High Efficiency Line Conditioners with Enhanced Performance for Operation with Non-Linear Loads
}

\begin{abstract}
This paper presents the analysis, design and experimental performance verification of a serial type line conditioner. Since it processes only a fraction of the load power, the overall converter losses tend to be lower and the efficiency of the conditioner higher. Regarding the dynamic performance, the line inductance, which results in a positive zero in the transfer function of the plant, is taken into consideration when designing a voltage controller with higher bandwidth for faster response. In addition, a virtual resistance is included in the control of the system to damp oscillations often seen for operations at light load and with non-linear load conditions. Experimental results obtained with a $10 \mathrm{kVA}$ prototype of a serial line conditioner fed from the load side and the proposed feedback control scheme are presented to demonstrate the superior performance of the line conditioner.
\end{abstract}

Index Terms - line conditioners, ac-ac converter, feedback control.

\section{INTRODUCTION}

AC line conditioners are frequently used to feed sensitive loads where the energy supply is of poor quality. They can be classified into two groups: Non-serial and serial [1]. While the former type has to process the entire load power, the latter handles only a fraction of it, what should yield higher efficiencies. Also, line conditioners can be classified according to the type of ac-ac converter they employ: indirect [1] and direct [2,3]. In the first case, there is an intermediate dc bus, with or without a large energy storage element, what allows the use of two conventional full-bridge converters in single-phase applications. In the second case, there are no storage elements and the converters usually require switches that are bi-directional in voltage and current and present the typical commutation issues of the direct ac-ac converters that have been addressed using a number of approaches [1-6]. These are usually of difficult implementation, expensive, lossy or unreliable [2].

The high efficiency line conditioners discussed in this paper are based on the principles of serial voltage compensation and of indirect ac-ac conversion. As shown in Fig. 1, serial type line conditioners can be represented by a controllable ac voltage source connected in series between the source and the load $\left(Z_{L}\right)$. They only provide the difference between the desired sinusoidal reference at the output voltage $\left(v_{0}\right)$ and the grid voltage, including the fundamental $\left(V_{d s F}\right)$ and harmonic $\left(V_{d s H}\right)$ components. In general, for regulating the fundamental component of the voltage across the load, the line conditioner needs to control the active power flow between the ac grid and load, thus requiring an ac-ac converter for implementation. The indirect type ac-ac converter employed in this line conditioner is shown in Fig. 2. It consists of two full-bridge converters controlled with conventional dead-times and no commutation issues.
Regarding the design of the control loops of line conditioners, it has been shown in [7] that the presence of line impedance $\left(Z_{S}\right)$ gives rise to a positive zero on the transfer function of the plant and can have a considerable impact on the dynamic performance of the line conditioner, especially when it feeds non-linear loads. Abrupt load current variations will results in large voltage drops across the grid inductance, reducing the voltage at the input terminals of the line conditioner $\left(v_{i}\right)$ making it difficult for injecting the right amount compensating voltage $\left(v_{d s}\right)$. For line conditioners employing indirect ac-ac converters, as in this paper, the line inductance problems are more critical as fast control response is required to allow effective voltage compensation, especially around the zero crossing of the grid voltage. In this paper, the line inductance is included in the transfer function that models the line conditioner and means to improve the dynamic performance of the system are discussed. Recall that the right hand side zero is a well-know problem of boost converters and effective solutions have been presented in [8]. To deal with the lightly damped oscillations that appear when line conditioners operate with light load or non-linear loads, a virtual resistance which has been previously applied to dc-dc converters [9] and [10] is employed.

This paper is organized as follows. In Section II, highly efficient line conditioner topologies using full-bridge converters are discussed. By changing the position from where the ac-ac converter is fed (line or load side), and/or rearranging the passive filter and transformer, several line conditioners are derived. A study to calculate the total efficiency of $10 \mathrm{kVA}$ line conditioners employing commercial components for operation with linear and nonlinear loads is conducted. In Section III, a line conditioner with load side serial voltage compensation is studied in detail. The line inductance is taken into account in the mathematical model, altering the converter's transfer function. A suitable control scheme for this plant model using classical control theory and a virtual resistance is presented in Section IV. Finally, in Section V experimental analyses are presented to demonstrate the superior performance and the feasibility of the proposed system.

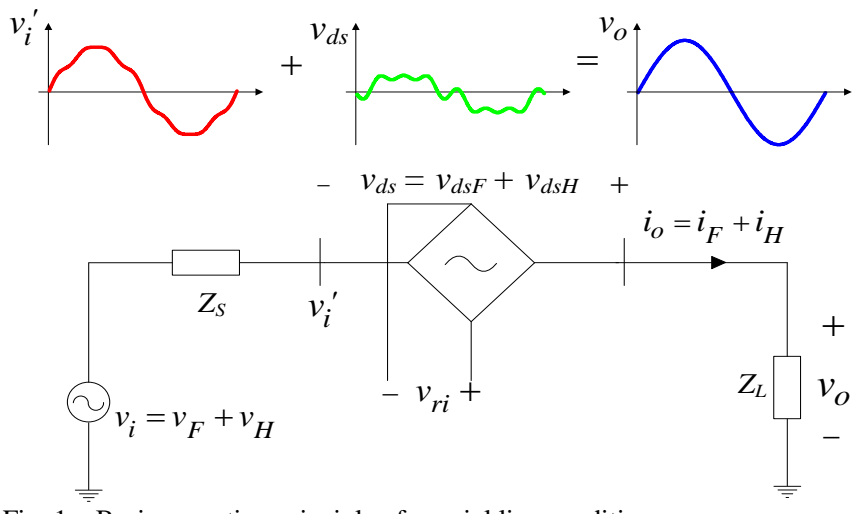

Fig. 1 - Basic operation principle of a serial line conditioner. 


\section{HIGH EFFICIENCY LINE CONDITIONERS}

In this section, highly efficient line conditioner topologies using two conventional full-bridge converters are presented. In addition, the total efficiency of two $10 \mathrm{kVA}$ line conditioners, one fed from the line and the other from the load side, employing commercial components and operating with linear and non-linear loads is determined analytically.

\section{A. High Efficiency Line Conditioner Topologies}

In [3], high efficiency line conditioner topologies derived from half-bridge, full-bridge and push-pull concepts were presented. Therein, a comparative evaluation of the proposed line conditioners employing direct ac-ac converters concerning characteristics, implementation complexity and component stress is presented. It was shown that line conditioners based on full-bridge converters with three-level modulation require magnetic components (inductor and transformer) with the lowest power rating among the analyzed structures. This feature is particularly interesting due to the fact that these elements are the components which determine the power density of the system. The main drawback of these conditioners is the large number of semiconductors, which increases the total cost of the structure.

Due to the lower power rating of the magnetic components and relatively low semiconductor loss characteristics, the line conditioners based on full-bridge ac-ac converters shown in Fig. 2 are considered in this paper.

\section{B. Line Conditioner Topologies Performance Evaluation}

The ac-ac converter shown in Fig. 2 can be analyzed as an indirect ac-ac converter without storage elements on the dclink (cf. [2]). In this way, the output voltage of the rectifier, $v_{r}$, is the input voltage of the inverter, which is adjusted to match the input voltage, $v_{r i}$, in phase.

Several voltage conditioners can be derived by combining the ac-ac converter of Fig. 2 and the principle of serial voltage compensation shown in Fig. 1. Fig. 3 presents eight line conditioner topologies created using the ac-ac converter, changing the position from where it is fed (line or load side), and/or rearranging its output filter elements $\left(L_{o}\right.$ and $\left.C_{o}\right)$ and isolation transformer $\left(T_{1}\right)$. They all have the advantage of processing only part of the power of the load, yielding higher efficiencies.
In order to determine the efficiency of serial line conditioners with indirect ac-ac converters based on two fullbridges operating with linear and non-linear loads, the topologies proposed in Fig. 3(c) and 3(g) are fully designed employing commercial components, according to the following specifications:

1) Input and output voltages rms values $\mathrm{v}_{\mathrm{i}}=220 \mathrm{~V} \pm 20 \% / 60$ $\mathrm{Hz}$ and $\mathrm{v}_{\mathrm{o}}=220 \mathrm{~V} / 60 \mathrm{~Hz}$;

2) Power rating $S_{o}=10 \mathrm{k} \mathrm{VA}$;

3) Switching frequency $f_{s}=20 \mathrm{k} \mathrm{Hz}$;

4) Allowed current and voltage ripples in the output filter inductor $\Delta \mathrm{I}_{\mathrm{Lo}}=10 \% \mathrm{I}_{\mathrm{Lo} \_\mathrm{pk}}$ and capacitor $\Delta \mathrm{V}_{\mathrm{Co}}=1 \% \mathrm{~V}_{\mathrm{o} \_\mathrm{pk}}$.

The transformer turns ratio $\left(n_{1}\right)$ was defined in such a way that all systems have similar static gain for a given duty cycle $(D)$ and allowed input voltage range $\left(v_{i}=220 \mathrm{~V} \pm 20 \%\right)$. This allows the topologies to have equivalent control efforts and dynamic behavior in the considered operation points. The value of $n_{1}$ also considers the voltage drop across the switches of the ac-ac converter, output filter and transformer. For the linear load analysis a resistor is used, whilst for the non-linear load a $10 \mathrm{~kW}$ single-phase full-bridge diode rectifier is considered.

Table I lists the line conditioner components, including the stresses on the power components and the resulting power losses for operation with linear and non-linear loads at different $r m s$ values of the input voltages. Therein, the power losses from the semiconductors were predicted according to [11], where the total losses were determined directly in the circuit simulator. The instantaneous semiconductor current is combined with the conduction and switching loss characteristics by a second order equation using fitted coefficients obtained from data-sheets. The inductor and transformer losses consider core and copper losses, whilst the capacitor loss considers dielectric and thermal losses. Finally, the auxiliary power supply for fans, driver and control board $\left(\mathrm{P}_{\mathrm{aux}}=30 \mathrm{~W}\right)$ as well as an additional share of the losses for the PCB and various other distributed losses $\left(\mathrm{P}_{\text {dist }}=20 \mathrm{~W}\right)$ are assumed to be constant.

When analyzing the data compiled in Table I, it can be seen that the power handled by the ac-ac converter and isolation transformer differ according to whether it is fed from the line or load side and it is also strongly dependent on the required voltage compensation $v_{d s}=\Delta \cdot v_{0}$. Overall, both topologies presented very high efficiency, of $97 \%$ and above.

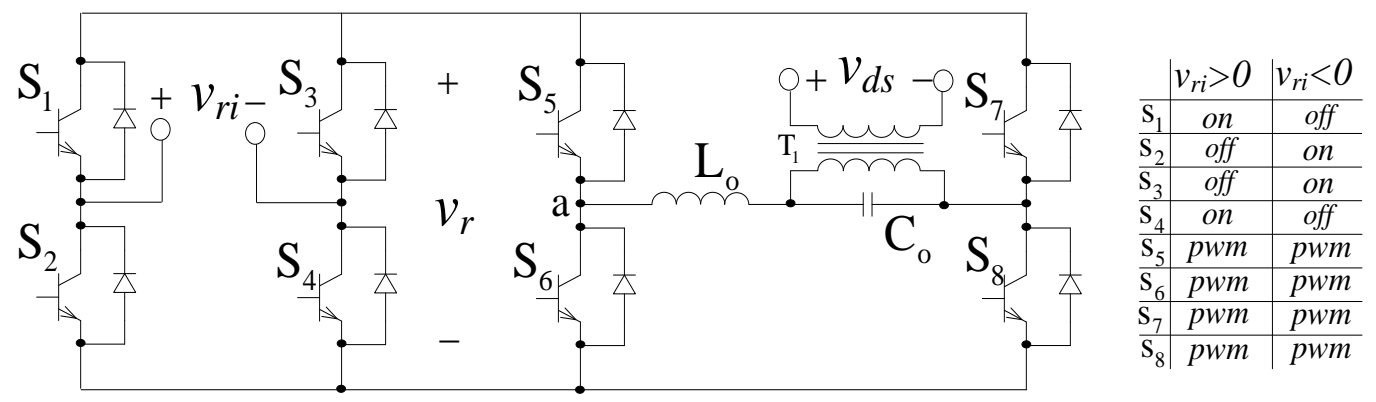

Fig. 2 - Ac-ac converter based on full-bridge converter. 

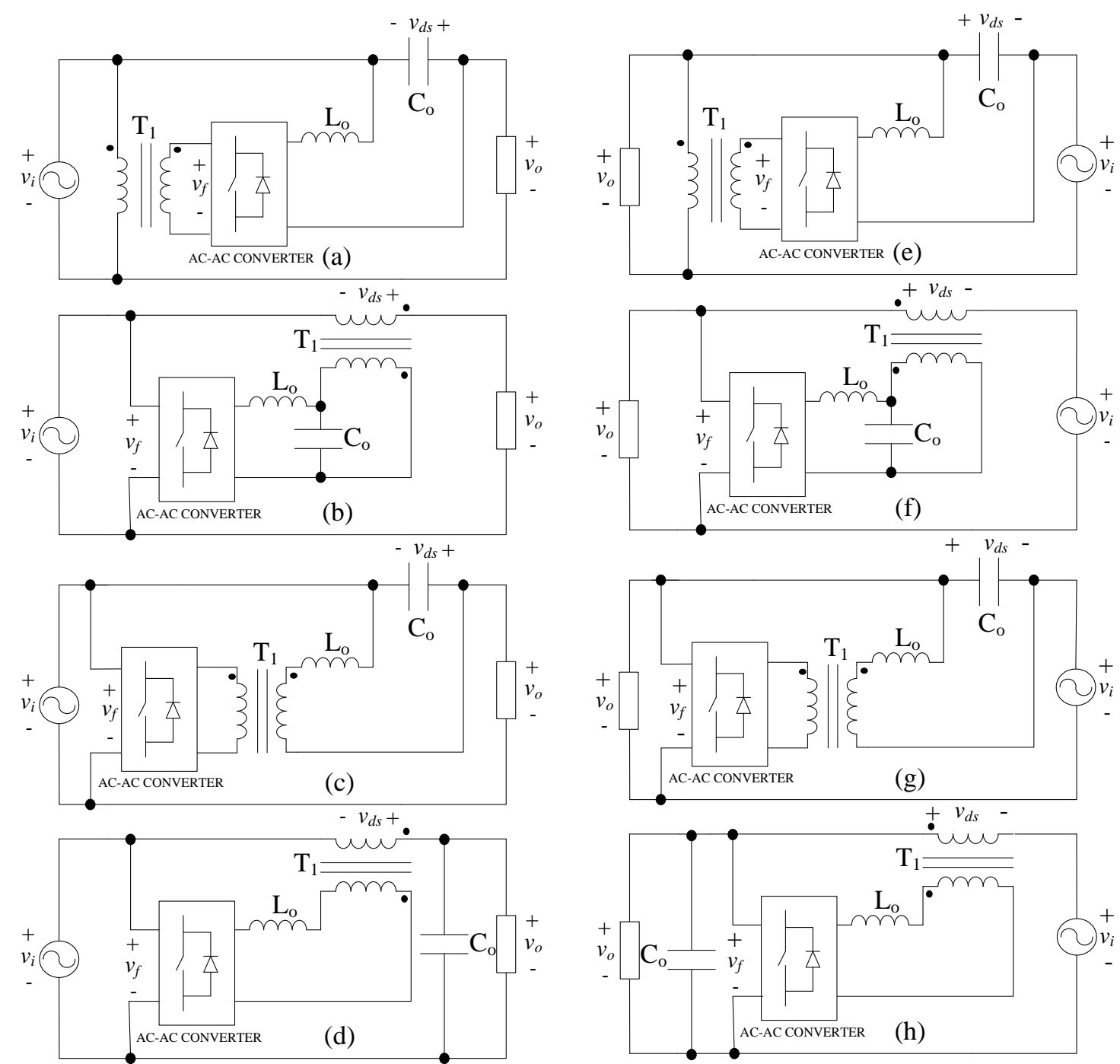

Fig. 3- Line conditioner topologies with ac-ac converter fed by: (a-d) the line side; and (e-h) by the load side.

TABLE I

$10 \mathrm{kVA}$ line conditioner comparative evaluation.

\begin{tabular}{|c|c|c|c|c|c|c|c|}
\hline \multicolumn{2}{|c|}{ Topology } & \multicolumn{3}{|c|}{$\begin{array}{l}\text { Indirect line conditioner with } \\
\text { direct link supplied on the line side }\end{array}$} & \multicolumn{3}{|c|}{$\begin{array}{c}\text { Indirect line conditioner with direct } \\
\text { link supplied on the load side }\end{array}$} \\
\hline \multicolumn{2}{|c|}{ Operation Point } & $\mathrm{V}_{\mathrm{i}}=220+20^{\circ}$ & $\mathrm{V}_{\mathrm{i}}=220 \mathrm{~V}$ & $\mathrm{~V}_{\mathrm{i}}=220-20 \%$ & $V_{i}=220+20 \%$ & $\mathrm{~V}_{\mathrm{i}}=220 \mathrm{~V}$ & $\mathrm{~V}_{\mathrm{i}}=220-20 \%$ \\
\hline \multirow{2}{*}{$\begin{array}{c}\text { Total semiconductor } \\
\text { power loss }\end{array}$} & Non-linear load & $117.4 \mathrm{~W}$ & $77.63 \mathrm{~W}$ & $111.5 \mathrm{~W}$ & $74.5 \mathrm{~W}$ & $63.1 \mathrm{~W}$ & $125.16 \mathrm{~W}$ \\
\hline & Linear resistive load & $114.11 \mathrm{~W}$ & $89.75 \mathrm{~W}$ & $103.1 \mathrm{~W}$ & $85.94 \mathrm{~W}$ & $76.3 \mathrm{~W}$ & $124.6 \mathrm{~W}$ \\
\hline \multirow{2}{*}{ Capacitor power loss } & Non-linear load & $0.1 \mathrm{~W}$ & $5 \mathrm{~mW}$ & $60 \mathrm{~mW}$ & $0.55 \mathrm{~W}$ & $33 \mathrm{~mW}$ & $0.45 \mathrm{~W}$ \\
\hline & Linear resistive load & $10 \mathrm{~mW}$ & & & & & $0.19 \mathrm{~W}$ \\
\hline \multirow{2}{*}{$\begin{array}{c}\text { Transformer/Inductor } \\
\text { power loss }\end{array}$} & Non-linear load & $60 / 3$ & $59 / 31 \mathrm{~W}$ & $62 / 37 \mathrm{~W}$ & $56 / 1$ & $8 \mathrm{~W}$ & $0 \mathrm{~W}$ \\
\hline & Linear resistive load & $61 / 25 \mathrm{~W}$ & $59 / 23 \mathrm{~W}$ & $61 / 25 \mathrm{~W}$ & $46 / 1$ & $54 / 12 \mathrm{~W}$ & $77 / 21 \mathrm{~W}$ \\
\hline \multicolumn{2}{|c|}{ Auxiliary power supply $\left(\mathrm{P}_{\mathrm{aux}}\right)$} & $30 \mathrm{~W}$ & $30 \mathrm{~W}$ & $30 \mathrm{~W}$ & $30 \mathrm{~W}$ & $30 \mathrm{~W}$ & $30 \mathrm{~W}$ \\
\hline \multicolumn{2}{|c|}{ Various distributed losses $\left(\mathrm{P}_{\text {dist }}\right)$} & $20 \mathrm{~W}$ & $20 \mathrm{~W}$ & $20 \mathrm{~W}$ & $20 \mathrm{~W}$ & $20 \mathrm{~W}$ & $20 \mathrm{~W}$ \\
\hline \multirow{2}{*}{$\begin{array}{c}\text { Total power loss } \\
\text { [W]/ Efficiency [\%] }\end{array}$} & Non-linear load & 259/97.41 & $218 / 97.82$ & $260 / 97.4$ & $194 / 98.06$ & $201 / 98$ & $300 / 97$ \\
\hline & Linear resistive load & $250 / 97.5$ & $221.7 / 97.8$ & 239/97.61 & $192 / 98.08$ & 192/98.08 & $273 / 97.27$ \\
\hline \multicolumn{8}{|c|}{ System Characteristics } \\
\hline \multicolumn{2}{|c|}{ Inductive Filter $\mathrm{L}_{0}$ (core, number of turns) } & \multicolumn{3}{|c|}{$1 \mathrm{mH}(2 \mathrm{xEE} 80 / 38 / 20$ and 65 turns $)$} & \multicolumn{3}{|c|}{$0.6 \mathrm{mH}(2 \mathrm{xEE} 80 / 38 / 20$ and 41 turns $)$} \\
\hline \multicolumn{2}{|c|}{ Capacitive Filter $\mathrm{C}_{0}$} & \multicolumn{3}{|c|}{$10 \mu \mathrm{F}(\mathrm{EPCOS} \mathrm{B} 32360)$} & \multicolumn{3}{|c|}{$20 \mu \mathrm{F}$ (EPCOS B32360) } \\
\hline \multicolumn{2}{|c|}{ Transformer Turns Ratio (core, prim./sec. turns) } & \multicolumn{3}{|c|}{$\mathrm{n}_{1}=3.2$ (2xlamin.EI225, 50/16 turns) } & \multicolumn{3}{|c|}{$\mathrm{n}_{1}=4$ (2xlamin.EI225, 63/16 turns) } \\
\hline \multicolumn{2}{|c|}{ Power Modules } & \multicolumn{3}{|c|}{ 4xSKM50GB063D } & \multicolumn{3}{|c|}{ 4xSKM50GB063D } \\
\hline
\end{tabular}




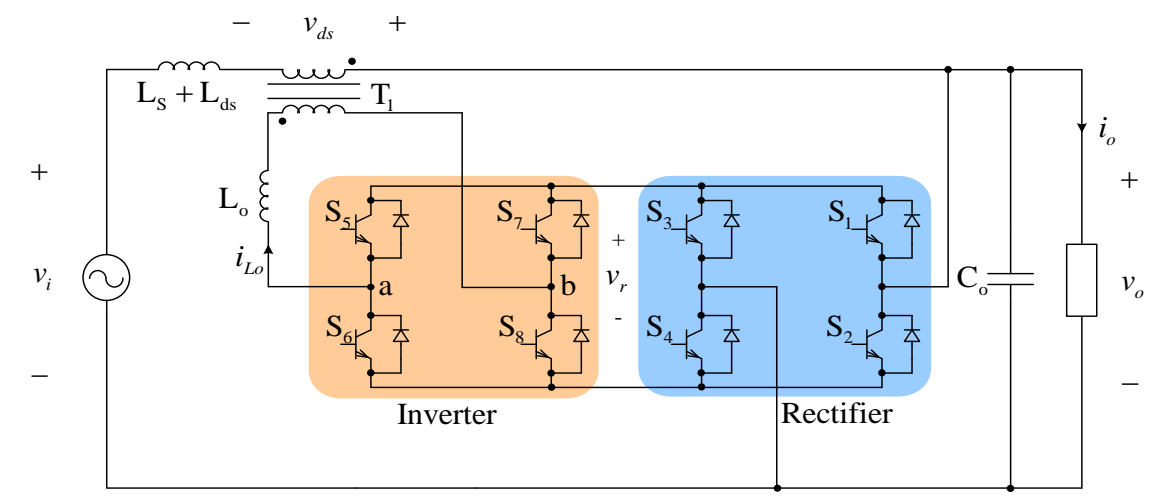

Fig. 4 - Line conditioner’s topology.

\section{LINE CONDITIONER ANALYSIS}

In this section, a serial line conditioner fed from the load side is studied in detail. The line-impedance is taken into account in the mathematical model, transfer function, of the system. Thus, a better understanding of the system's dynamic behavior is achieved and a more suitable control stage can be designed.

\section{A. Conditioner Characteristics}

The topology depicted in Fig. 4 was chosen to implement and to validate the proposed study. The isolation transformer $\left(T_{1}\right)$, at the output of the converter, always decreases the voltage and its role is to add the compensation voltage to or subtract it from the grid voltage.

Observe in Fig. 4 that the capacitive element of the filter $\left(C_{o}\right)$ is placed in parallel to the load. This enhances the dynamic of the output voltage, due to the fact that the capacitor provides energy for sudden variations in the load currents, and subsequently reduces the voltage variations [12]. Moreover, the ac-ac converter is fed from the load side, thus the input voltage for the rectifier is taken from the output capacitor $\left(C_{o}\right)$. In this way, the switches are more protected against over-voltage than if the rectifier is fed from the line side.

As shown in Table I, the power processed by the ac-ac converter depends on the voltage compensation region and factor $\Delta(-20 \% \leq \Delta \leq 20 \%)$. For similar values of $\Delta$, the system will be more efficient for decreasing $(0 \%<\Delta \leq 20 \%)$ than for increasing compensation $(-20 \% \leq \Delta<0 \%)$.

Due to the position of the capacitor $C_{o}$, the leakage inductance $\left(L_{d s}\right)$ of the transformer along with the inductance $\left(L_{S}\right)$ of the grid aids the filtering of the output voltage. As a result, in the event that a pre-filter is not used on the input of the line conditioner, the system would not require an extra filtering inductor $\left(L_{o}\right)$. In this case, the sum of the transformer and the grid's intrinsic inductances $\left(L_{d s}+L_{S}\right)$, referred to the primary side of the transformer, should be enough to filter the switching harmonics present in the output voltage of the inverter.

\section{B. Converter's Main Analytical Expressions}

The duty cycle $(D)$ of the ac-ac converter is defined as the ratio between the interval when the switches $S_{5}$ and $S_{8}$ conduct simultaneously, and the switching period $T_{S}$. This for the positive semi-cycle of $v_{o}$. On the negative semi-cycle, $D$ is defined as the ratio between the interval when $S_{6}$ and $S_{7}$ conduct simultaneously, and $T_{S}$.

The voltage at the input of the line conditioner can have an amplitude variation of $A$ from the rated output voltage. The expressions (1) and (2) give the turns ratio of the transformer, $n_{1}$, and the converter static gain, $g(t)$, where $D_{\max }$ is the maximum allowed duty cycle.

To design the output filter elements, it is necessary to know the maximum allowed voltage and current ripples. Considering all circuit inductances referred to the transformer secondary side as Leq, (3) gives the current ripple $\Delta I_{\text {Leq }}$, where $f_{s}$ is the switching frequency. The voltage ripple across $C_{o}, \Delta V_{C o}$, for full load operation, is calculated by (4), where $I_{o}$ is defined as the maximum rms load current.

In order to analyze the dynamic response of the system, its small signal model is determined as a dc equivalent circuit modeled at the input voltage's peak value. Fig. 5 shows the block diagram of the line conditioner. The impact of the grid voltage and duty cycle of the ac-ac converter on the output voltage is given by (5). $G(s)$ is defined by (6) and $F(s)$ by (7), respectively. $R$ is the equivalent distributed resistance in the main path of the line conditioner.

Analyzing (6), one can see that $G(s)$ contains a zero on the right-half-plane (RHP) which depends on the line and load characteristics. This kind of system, often referred to as nonminimum phase, has a unique step input response. The effect of the positive zero can be interpreted as a delay to the output voltage response due to duty cycle variations. Observe that if a very fast control loop is used, the changing dynamic of the control signal can lead the system to an unstable operation.

To study the influence of the load on the dynamic response of the system, a resistive load is assumed for $Z_{L}$. Fig. 6 shows a Bode diagram of expression (6) for two different load values. It can be observed that the dynamic of the system is more oscillatory and less damped as the load impedance increases. Therefore, in closed loop operation the topology can have stability problems, e.g. when feeding nonlinear loads such as diode bridge rectifiers, where the current can become discontinuous and have abrupt variations.

In this work, a control strategy based on the virtual resistance concept presented in [9] is used to address the cases of light load conditions and voltage oscillations originating from grid side and/or load disturbances. 


$$
\begin{gathered}
n_{1}=\frac{v_{d p}(t)}{v_{d s}(t)}=\frac{1}{\Delta} \cdot D_{\text {max }} \\
g(t)=\frac{v_{o}(t)}{v_{i}(t)}=\frac{n_{1}}{n_{1}-D} \\
\Delta I_{\text {Leq }}=\frac{V_{0} \cdot D \cdot(1-D)}{2 \cdot n_{1} \cdot f_{s} \cdot L_{e q}} \\
\Delta V_{C o}=\frac{I_{0} D(1-D)}{2 f_{s} C_{0}\left(n_{1}-D\right)} \\
\left.G(s)\right|_{\hat{v_{i}}=0}=\frac{-s L_{e q} \frac{I_{0} n_{1}^{2}}{n_{1}-D} Z_{L}+\left(Z_{L} V_{0}\left(n_{1}-D\right)-R \frac{I_{0} n_{1}^{2}}{n_{1}-D} Z_{L}\right)}{s^{2} C_{0} Z_{L} L_{e q} n_{1}^{2}+s n_{1}^{2}\left(L_{e q}+C_{0} Z_{L} R\right)+\left(Z_{L}\left(n_{1}-D\right)^{2}+R n_{1}^{2}\right)} \\
\left.F(s)\right|_{\hat{d}=0}=\frac{Z_{L} n_{1}\left(n_{1}-D\right)}{s^{2} C_{0} Z_{L} L_{e q} n_{1}^{2}+s n_{1}^{2}\left(L_{e q}+C_{0} Z_{L} R\right)+\left(Z_{L}\left(n_{1}-D\right)^{2}+R n_{1}^{2}\right)}
\end{gathered}
$$

\section{LINE CONDITIONER CONTROL}

The feedback control of the line conditioner is implemented with three loops. The main loop provides the conditioning of the output voltage with the fastest response. The second loop is incorporated into the main loop to control the dc voltage level in the transformer windings, avoiding its saturation. Finally, the last loop incorporates the virtual resistance concept into the main loop in order to damp the output voltage oscillations, which could appear during disturbances, light and/or non-linear load operation. Fig. 7 shows the complete diagram of the proposed closed loop of the line conditioner.

\section{A. Voltage Control Loop}

The voltage controller is designed using the classical PID control methodology [13] and [14]. This design is done for light load operation, which is considered the critical case due to the high voltage oscillations that can occur in this condition. To generate the sinusoidal reference a microcontroller was used. By detecting the zero crossing of the output voltage the template of a sinusoidal waveform stored in the memory is used to produce the reference signal. This procedure facilitates the synchronization that must be performed between the input and output voltages of the converter [15]. Another advantage of digitally implementing the reference signal is the possibility to adjust its frequency according to small variations in the line frequency. It can be remarked that in cases where the grid voltage presents high harmonic content, multiple zero crossings of the sensed voltage signal may occur, which could lead to operational problems. In this case, synchronization by PLL circuits is recommended [16].

\section{B. Current Control Loop}

The current control loop aims to eliminate the average voltage in the $T_{1}$ transformer, without interfering with the operation of the voltage control loop. This control is used to

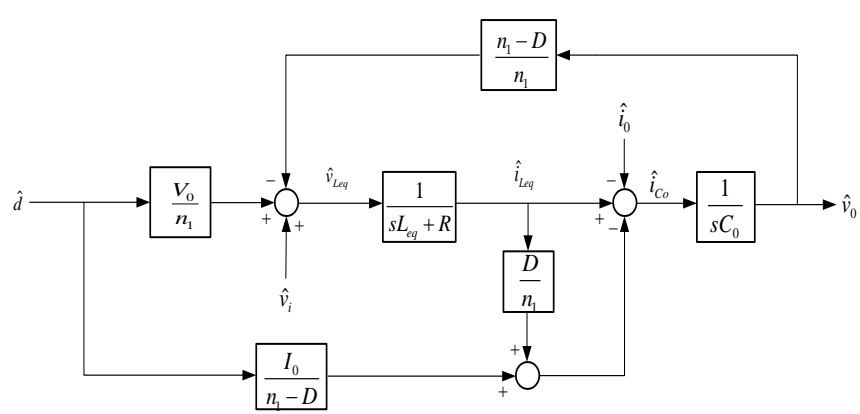

Fig. 5 - System’s block diagram.

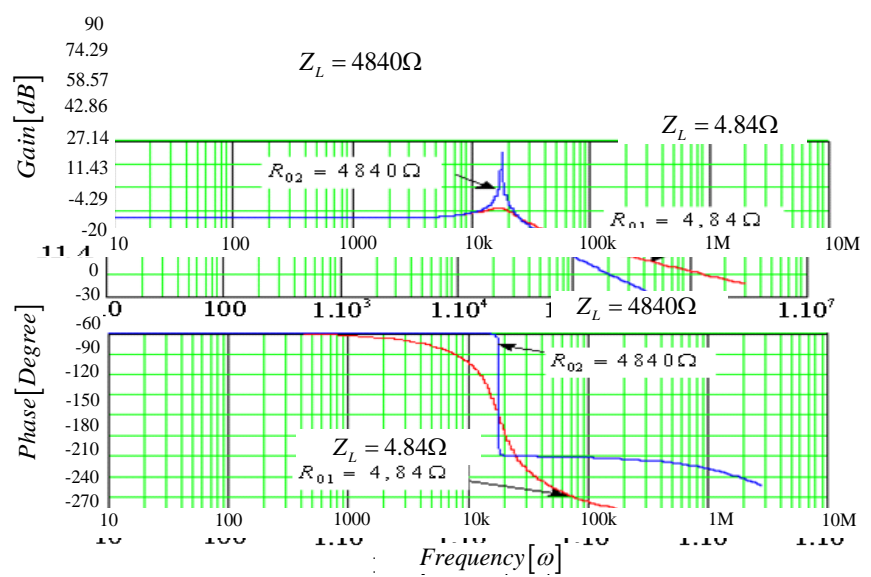

Fig. 6 - Bode diagram of G(s): Magnitude and phase.

avoid the saturation of the core of the transformer, and also to protect the system from modulator or switch faults that could lead the voltage loop to saturation.

The current control is implemented by monitoring the current of the transformer and by comparing it to a zero value of reference. The error signal generated is compensated using a proportional and integral (PI) controller, with crossover frequency around ten times smaller than the line frequency, to avoid interfering with the voltage loop.

In order to verify the functionality of the proposed current control loop in a circuit simulator, an average value is applied to the output voltage reference, after an instant $t_{0}$. In this situation, it is expected that the inverter generates an average current in the primary winding of the transformer. Fig. 8 shows the simulation results for the line conditioner operation with and without the proposed current control loop. Therein, one can observe that this control loop can effectively eliminate the average value of current in the transformer in just a few periods of the grid voltage.

\section{Virtual Resistance Control Loop}

The line conditioner's ability to provide a sinusoidal voltage with low harmonic content at the output is mainly dependent on the bandwidth of the voltage controller. In this way, the faster this control loop is, the better the quality of the voltage delivered to the load will be; however this could lead the system to instability. By using the virtual resistance loop concept, proposed in [9] and [10] for dc-dc converters, one can implement a voltage loop with larger bandwidth, without risking instability. In fact, this method provides an extra damping to voltage overshoot and oscillations, mainly during load variations. 
Fig. 9(a) shows the block diagram of the line conditioner with a virtual resistance connected in series to the equivalent inductance of the output filter $\left(L_{d s}\right.$ and $\left.L_{S}\right)$. The role of this resistor is to reduce the voltage across the output filter proportionally to the current which passes through it. The desired resistance of the series resistor determines the proportional gain, $R_{\text {Virtual }}$. Using circuit theory a virtual resistance, as shown in Fig. 9(b), can be repositioned in the loop in order to act over the control signal. In fact, the effect of $R$ in the circuit diagram is similar to the virtual resistance, $R_{\text {Virtual. }}$ Therefore, the expressions of $G(s)$ and $F(s)$ remain unaltered, only the $R$ value is replaced by, or added to, the $R_{\text {Virtual }}$ value.

Note that the virtual resistance controller injects a signal proportional to the load current into the control signal $v_{c}$ (c.f. Fig. 9(b)); therefore the saturation of the modulator limits this gain and further simulations of the system operating under maximal loading and transients are recommended.

\section{EXPERIMENTAL RESULTS}

\section{A. Converter specifications}

The following parameters characterize the implemented conditioner:

1) $V_{i}=220 \mathrm{~V} \pm 20 \%$ - input voltage $r m s$ value;

2) $V_{o}=220 \mathrm{~V}$ - output voltage $r m s$ value;

3) $S_{o}=10 \mathrm{kVA}$ - output power rating;

4) $f_{r}=60 \mathrm{~Hz}$ - grid frequency;

5) $f_{\mathrm{S}}=20 \mathrm{kHz}$ - switching frequency;

6) $n_{1}=4$ - transformer turns ratio;

7) $L_{e q}=150 \mu \mathrm{H}$ - transformer leakage + line inductance;

8) $C_{o}=20 \mu \mathrm{F}$ - output capacitor.

Control stage parameters (c.f. Fig. 7):

9) $G_{M v}=0.0114$ - voltage sensor gain;

10) $G_{M i}=0.33$ - current sensor gain;

11) $G_{P W M} / C_{R v}=0.16 / 0.066$ - modulator and virtual resistance gain;

12) $C_{v}(s)=(1+\mathrm{s} 100 \mu)^{2} /[\mathrm{s} 37 \mu(1+\mathrm{s} 10.7 \mu)]-$ voltage control;

13) $\mathrm{I}_{c}(\mathrm{~s})=10 / \mathrm{s}$ - current controller.

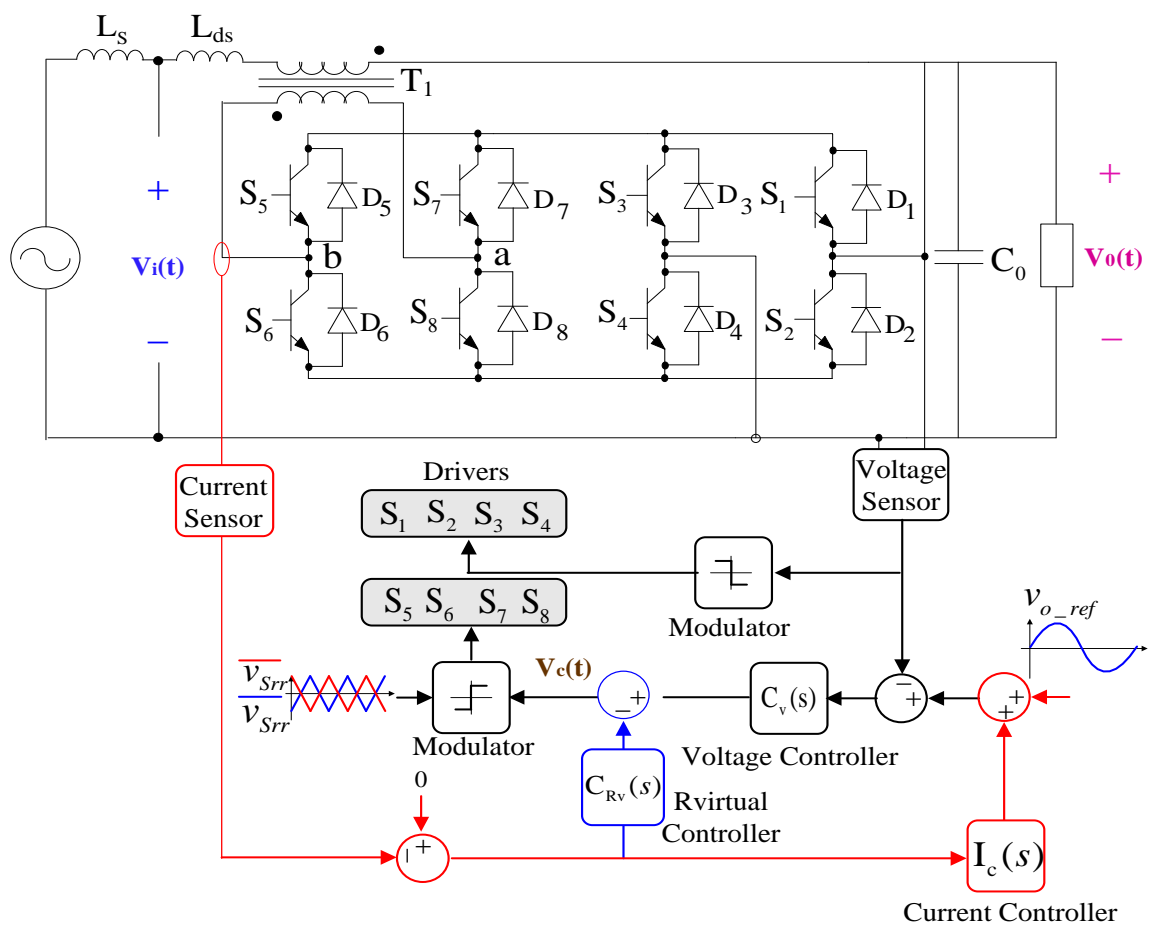

Fig. 7 - Overall control scheme used in the line conditioner.

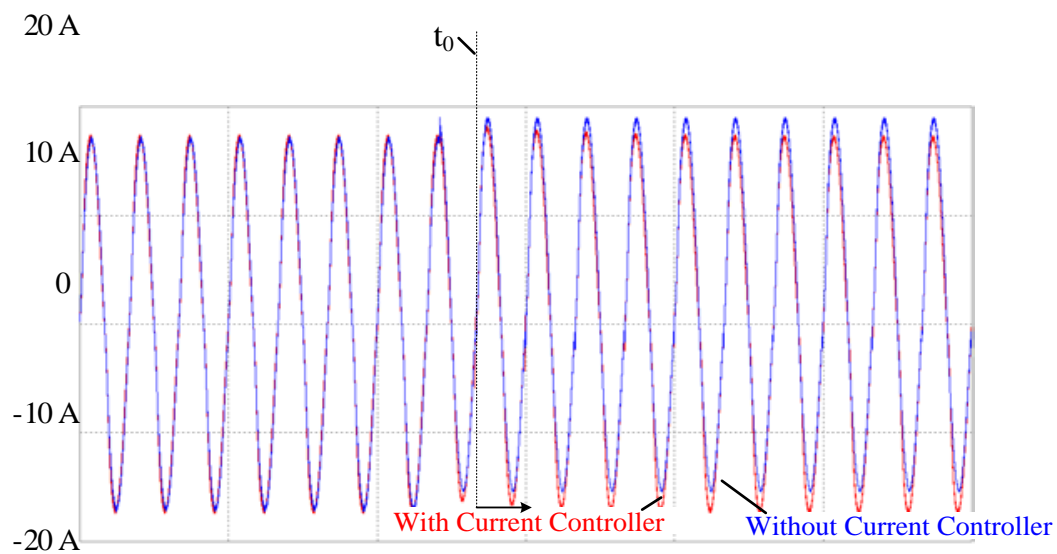

Fig. 8 - Performance of the current control avoiding saturation of the transformer. 


\section{B. Operation with load and input voltage transients}

Fig. 10 presents the experimental result for a $+50 \%$ power loading transient (idle to $5 \mathrm{~kW}$ ) for the system with and without the virtual resistance control loop. As can be observed, the virtual resistance increases the damping for the oscillating output voltage, leading to a system with better dynamic response than the system without it. By reducing overvoltage face disturbances, the virtual resistance loop gives an extra-safety margin for the load that is fed by the line conditioner leading to an enhanced output voltage dynamic performance.

The output voltage and control waveforms for a $+20 \%$ and $-20 \%$ transient in the input voltage, when feeding $2 \mathrm{~kW}$ to a resistive load, are shown in Fig. 11(a) and Fig. 11(b), respectively. For both test conditions, the converter can quickly correct the output voltage within $1 \mathrm{~ms}$.

\section{Operation with distorted input voltage}

Fig. 12 shows the performance of the line conditioner feeding $2 \mathrm{~kW}$ to a resistive load when operating with a distorted input voltage (THD $=4.16 \%$ ). The system provides an output voltage with a sinusoidal shape and with lower harmonic distortion (THD $=1.98 \%$ ).

\section{Operation with non-linear load}

Fig. 13 shows the output voltage, input current and control voltage waveforms for operation with a full-bridge diode rectifier. As can be observed, the output voltage displays a sinusoid shape with a low harmonic distortion (3.7\%). Moreover, the THD of the output voltage was below 5\%, and none of the harmonic components had a value larger than 3\%, following the limits of the standard IEEE 519/92.

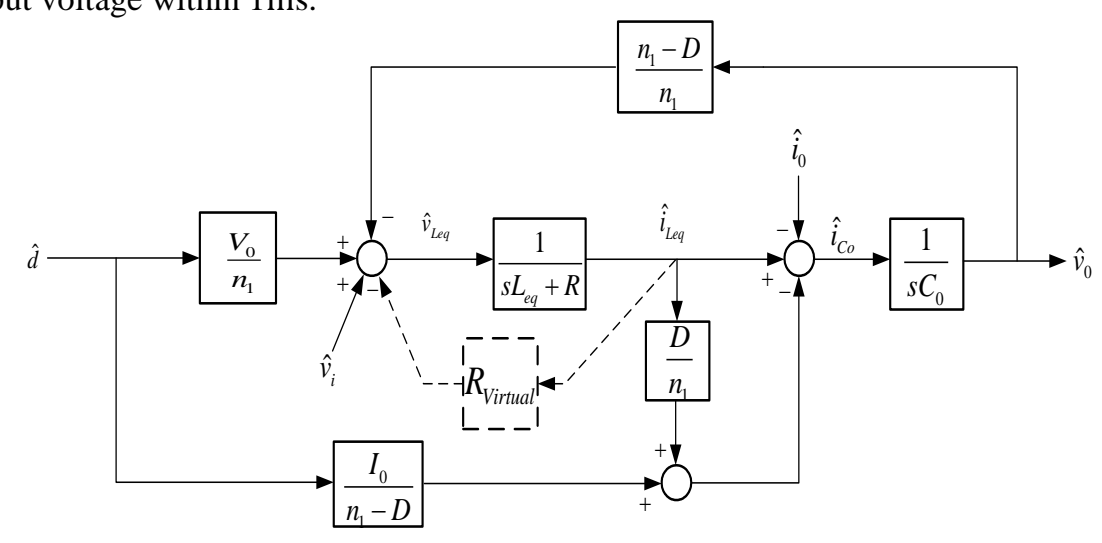

(a)

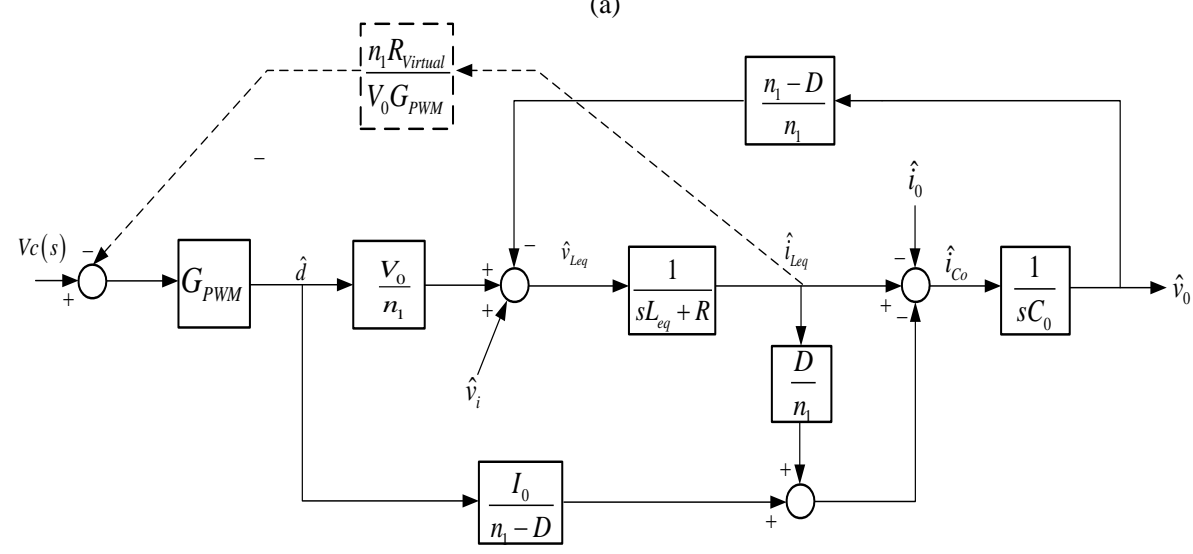

(b)

Fig. 9 - Implementation of the virtual resistance concept.

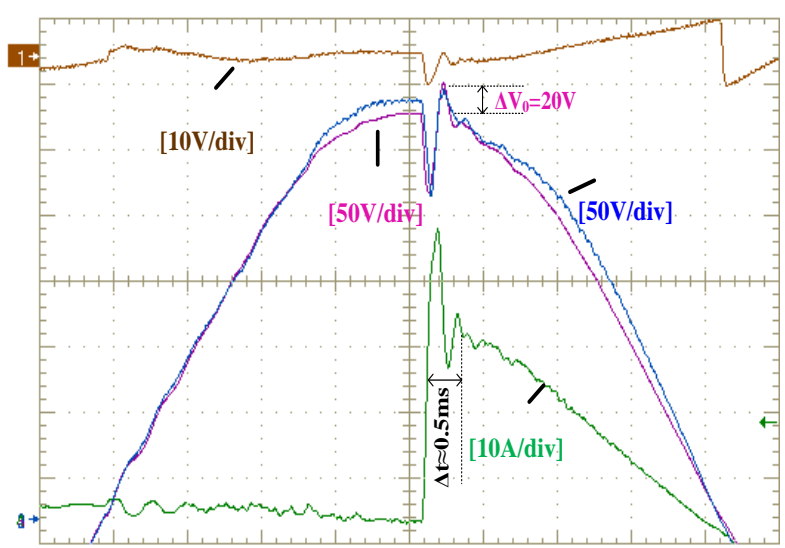

(a)

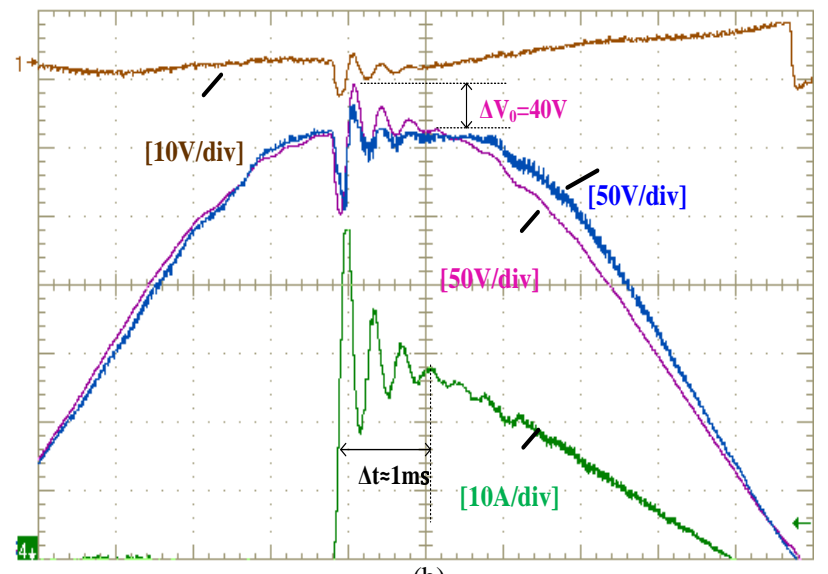

(b)

Fig. $10-+50 \%$ load variation: (a) with and (b) without virtual resistance (A resistive load is considered in this analysis). 


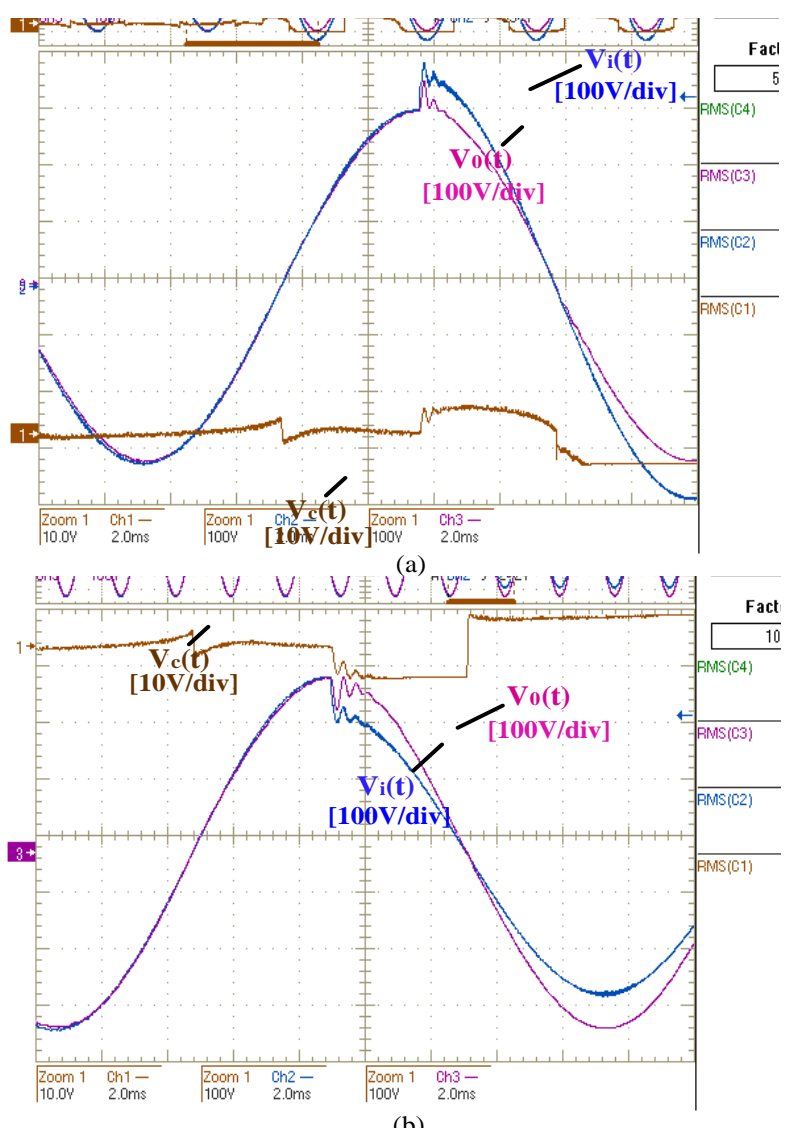

(b)

Fig. 11 - Input voltage transients: (a) $+20 \%$ and (b) $-20 \%$.

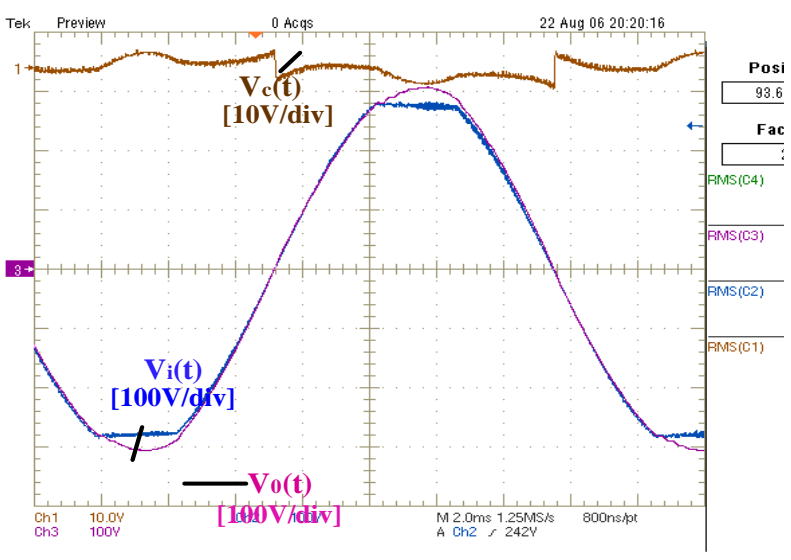

Fig. 12 - Operation with distorted input voltage.

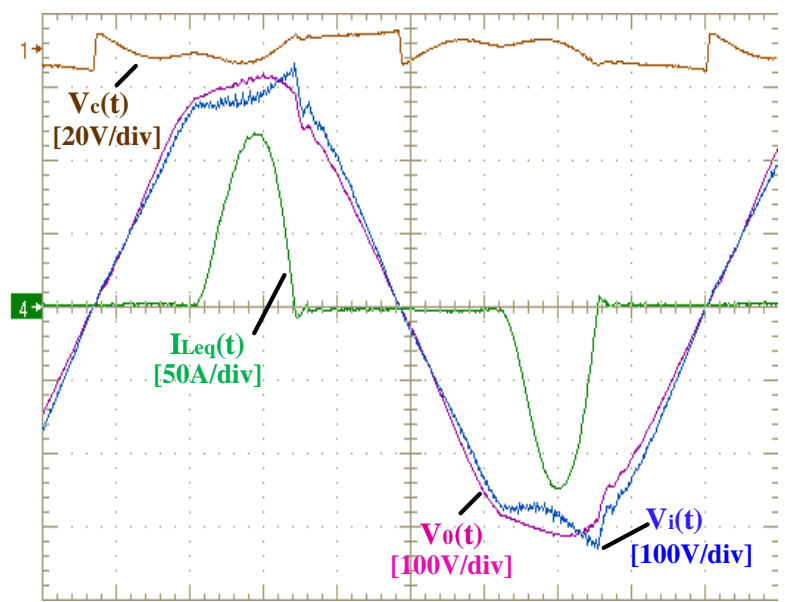

Fig. 13 - Operation with a non-linear load.

\section{CONCLUSIONS}

This paper has discussed serial type ac line conditioners based on indirect ac-ac conversion implemented with two full-bridges converters. Since the conditioner only processes part of the load power, the overall losses in the power converters are low and the line conditioners present high efficiency. This was demonstrated analytically for two possible topologies, one fed from the load side and the other from the grid side, for various conditions of input voltage and loads. The use of an indirect type ac-ac converter, without energy storage in the intermediate bus, did not compromise the ability of the line conditioner to regulate the fundamental component and mitigate harmonics due to input voltage distortions and nonlinear loads. Regarding the dynamic response of the system, a small signal model, including the grid inductance which creates a positive zero, was derived. Suitable linear controllers along with a virtual resistance loop were designed so as to increase the bandwidth and improve the damping of voltage oscillations that appear for light and nonlinear load conditions, thus leading to enhanced dynamic response. Experimental results of a $10 \mathrm{kVA}$ prototype were presented validating the analytical study presented on this high efficiency and high performance line conditioner for various cases of disturbance created by the grid and the load.

\section{REFERENCES}

[1] G. N. Patchett, "Automatic Voltage Regulators and Stabilizers," Great Britain, Pitman Press - Third edition - 1970.

[2] B. -H. Kwon, G. Y. Jeong, S. -H. Han and D. H. Lee, "Novel line conditioner with voltage up/down capability," IEEE Trans. on Ind. Electron., vol. 49, no 5, pp. 1110-1119, Oct. 2002.

[3] T. B. Soeiro, C. A. Petry, J. C. S. Fagundes and I. Barbi, "Direct AcAc Converters Using Commercial Power Modules Applied to Voltage Restorers," IEEE Trans. on Ind. Electron., vol. 58, no 1, January, 2011.

[4] J. H. Kim, B. D. Min, B. H. Kwon and S. C. Won, "A PWM buckboost AC chopper solving the commutation problem," IEEE Trans. on Ind. Electron., vol. 45, no 5, pp. 832-835, Oct. 1998.

[5] H. Y. Chu, H. L. Jou and C. L. Huang, "Transient response of a peak voltage detector for sinusoidal signals," IEEE Trans. on Ind. Electron., vol. 39, pp. 74-79, Feb. 1992.

[6] C. T. Pan and M. C. Jiang, "A Quick Response Peak Detector for Variable Frequency Three-Phase Sinusoidal Signals,” IEEE Trans. on Ind. Electron., vol 41, no. 4, pp. 434-440, Aug. 1994.

[7] C. A. Petry, J. C. S. Fagundes and I. Barbi, "Study of an Ac-Ac Indirect Converter for Application as Line Conditioner," in Proc. ISIE, pp. 757-762, Jun. 2005.

[8] D. M. Sable, B. H. Cho and R. B. Ridley, "Elimination of the Positive Zero in Fixed Frequency and Flyback Converters," in Proc. APEC, pp. 205-211, March, 1990.

[9] P. A. Dahono, "A Control Method for DC-DC Converter That Has an LCL Output Filter Based on New Virtual Capacitor and Resistor Concepts," in Proc. PESC, Aachen, Germany, 2004.

[10] A. M. Rahimi, and A. Emadi, "Active Damping in DC/DC Power Electronic Converters: A Novel Method to Overcome the Problems of Constant Power Loads," IEEE Trans. on Ind. Electron., vol. 56, no 5, pp. 1428-1439, May. 2009.

[11] U. Drofenik and J. W. Kolar, "A General Scheme for Calculating Switching- and Conduction- Losses of Power Semiconductors in Numerical Circuit Simulations of Power Electronic Systems”, in Proc. IPEC, Niigata, Japan, 2005.

[12] E. Meyer, Z. Zhang, F. L. Yan, “An Optimal Control Method for Buck Converters Using a Practical Capacitor Charge Balance Technique," IEEE Trans. on Power Electron., vol. 23, pp. 18021812, Jul. 2008.

[13] C. N. -M Ho, H. S. H. Chung, K.T.K. Au, "Design and Implementation of a Fast Dynamic Control Scheme for Capacitor- 
Supported Dynamic Voltage Restorers," IEEE Trans. on Power Electron., vol. 23, pp. 237-251, Jan. 2008.

[14] A. Prodic, "Compensator Design and Stability Assessment for Fast Voltage Loops of Power Factor Correction Rectifiers," IEEE Trans. on Power Electron. vol. 22, pp. 1719-1730, Sept. 2007.

[15] E. C. dos Santos, C. B. Jacobina and J. A. A. Dias, "Active power line conditioner applied to single-phase to three-phase systems," in Proc. 35th IECON, Porto, Portugal, Nov. 2009, pp. 148 - 153.

[16] C. E. M. Gomes, C. A. Petry and S. A. Mussa, "Multi-loop digital control of a line conditioner using DPLL," in Proc. 10th COBEP, Bonito, Brazil, Sep. 2009, pp. 791-796. 